\title{
Collicular Hyperactivation in Patients with COVID-19: A New Finding on Brain MRI and PET/CT
}

\author{
(D) A. Chammas, (D) C. Bund, (D)F. Lersy, (D).-C. Brisset, (D)F.-D. Ardellier, (D) S. Kremer, and (DI.J. Namer
}

\section{ABSTRACT}

SUMMARY: Hyperactivation of the colliculi has been observed in some patients with coronavirus disease 2019.

ABBREVIATIONS: ASL = arterial spin-labeling; COVID-19 = coronavirus disease 2019; SARS-CoV-2 = Severe Acute Respiratory Syndrome coronavirus 2

$\mathbf{R}$ ecent publications have described several brain abnormalities in patients with coronavirus disease 2019 (COVID-19), such as cerebral hemorrhage (including intraparenchymal hemorrhage or diffuse microhemorrhage), cerebral infarction, leukoencephalopathy, ${ }^{1,2}$ leptomeningeal enhancement, circumscribed or diffuse white matter signal abnormalities, posterior reversible encephalopathy syndrome, and focal intraparenchymal enhancement. ${ }^{3,4}$

In the $\left[{ }^{18} \mathrm{~F}\right]$ FDG-PET/CT, several patterns of abnormalities have been described, including frontal hypometabolism and cerebellar hypermetabolism ${ }^{5}$ and diffuse cortical hypometabolism (associated with putaminal and cerebellum hypermetabolism, compatible with encephalitis, and especially cerebellitis). ${ }^{6,7}$ In most of the cases, the underlying pathophysiological mechanism remains unknown.

Arterial spin-labeling (ASL) is increasingly used in neuroradiology as a diagnostic aid. ${ }^{8,9}$ Hyperperfusion is associated with hypermetabolism in PET/CT, suggesting that ASL could be considered as an alternative to $\left[{ }^{18} \mathrm{~F}\right] \mathrm{FDG}-\mathrm{PET} / \mathrm{CT} .{ }^{10}$

In the current brief, we report a new neuroradiological finding on MR imaging and PET/CT in patients with COVID-19.

\section{MATERIALS AND METHODS}

This retrospective study was carried out in the University Hospitals of Strasbourg and the Cancer Institute of Strasbourg Europe, from March 6, 2020, to August 13, 2020, on patients with COVID-19.

Received October 14, 2020; accepted after revision March 11, 2021.

From Hôpitaux Universitaires de Strasbourg (A.C., F.L., F.-D.A., S.K.), Service d'Imagerie 2, Hôpital de Hautepierre and Service de Médecine Nucléaire (C.B., I.J.N.), Institut de Cancérologie Strasbourg Europe Stasbourg, France, and Observatoire Français de la Sclérose en Plaques (J.-C.B.) Lyon, France.

Please address correspondence to: Prof Stéphane Kremer; Service d'Imagerie 2, Hôpital de Hautepierre, 1, Ave Molière, 67000 Strasbourg, France; e-mail: stephane.kremer@chru-strasbourg.fr

- Indicates open access to non-subscribers at www.ajnr.org

Indicates article with online supplemental data.

http://dx.doi.org/10.3174/ajnr.A7158
The study was approved by the ethical standards committee on human experimentation at Strasbourg University Hospital (CE2020-37) and was in accordance with the Declaration of Helsinki of 1964 and its subsequent amendments. Due to the emergency in the context of the COVID-19 pandemic responsible for the resurgence of acute respiratory and neurologic manifestations, the requirement for written informed consent from patients was waived. The final COVID-19 diagnosis was confirmed by real-time reverse-transcriptase polymerase chain reaction oropharyngeal swab test.

A total of 112 patients with neurologic symptoms who underwent brain 3T MR imaging were retrospectively included (age range, 25-87 years; mean age, 63.03 years; male-to-female ratio, $65 \% / 35 \%)$. Inclusion criteria were the following: age 18 years or older, positive Severe Acute Respiratory Syndrome coronavirus 2 (SARS-CoV-2) polymerase chain reaction swab test, and neurologic symptomatology that led to an MR imaging scan in the Strasbourg hospital. The mortality rate was $5 \%$. Patients had impaired consciousness ( 36 patients, $50 \%$ ), confusion (31 patients, $43 \%$ ), pyramidal tract signs (19 patients, $26 \%$ ), agitation (18 patients, 25\%), headaches (14 patients, 19\%), pathologic awakening (13 patients, $18 \%$ ), anosmia and ageusia (5 patients, $7 \%$ ), and seizures ( 3 patients, $4 \%$ ). Among them, $90 \%$ were hospitalized in the intensive care unit. The initial cerebral MR imaging was performed an average of 30 days after the onset of respiratory symptoms (SD, 15.92). Clinical, imaging, biologic, treatment, and progression data were collected and are detailed in the Results section (Online Supplemental Data). Categoric data were compared using Fisher exact test. Quantitative data were compared using Student $t$ test. A $P$ value lower than .05 was considered significant. Brain MR imaging anomalies were classified as follows: leptomeningeal enhancement, multifocal and circumscribed FLAIR white matter hyperintensities, diffuse white matter FLAIR hyperintensities, white matter microhemorrhages, ischemic stroke, focal enhancement, FLAIR hyperintensities involving the mesial temporal lobe, and posterior reversible encephalopathy syndrome. 

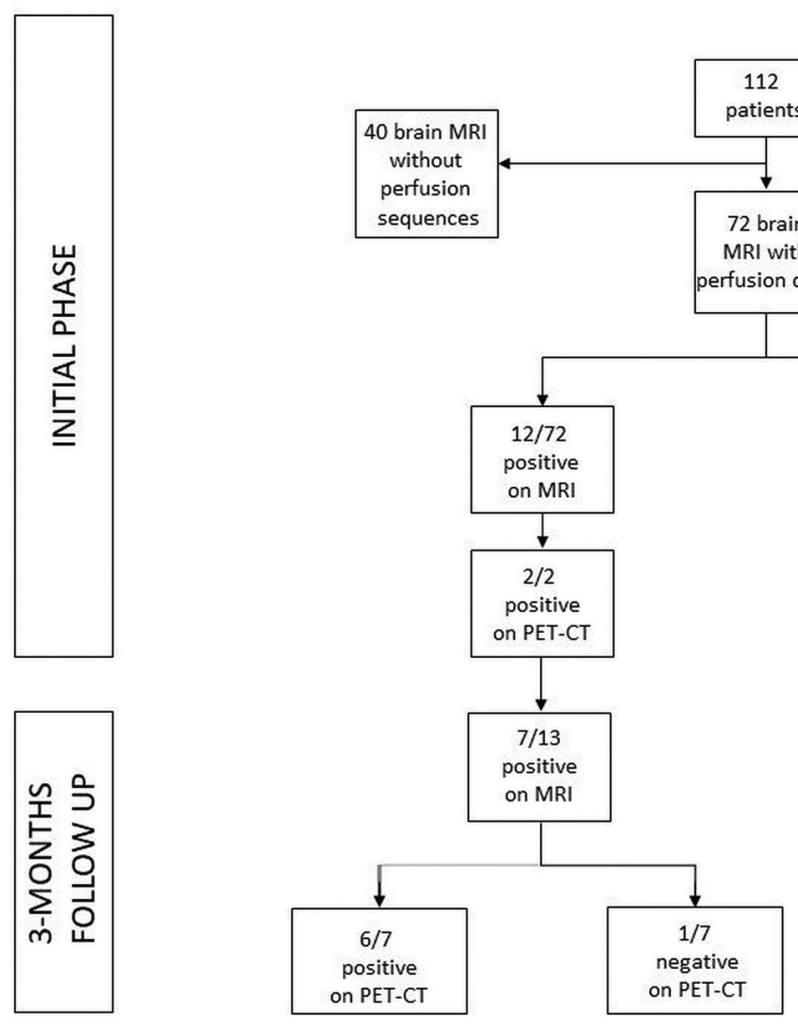

FIG 1. In the acute phase of COVID-19 infection, among the 72 patients with the ASL sequence, 12 of them showed hyperperfusion of their colliculi (defined as positive findings on MR imaging) and 60 of them did not (defined as negative findings on MR imaging). Among the 12/72 with positive findings on MR imaging, 2 underwent a PET/CT that showed hyperactivation. At the 3-month follow-up, 13 patients had brain MR imaging with 7 of them showing hyperperfusion of their colliculi, confirmed by PET/CT in 6 patients. Among the $6 / 13$ patients who had no hyperperfusion of their colliculi on MR imaging, all of the PET/CTs that were obtained (5/5) were also negative.
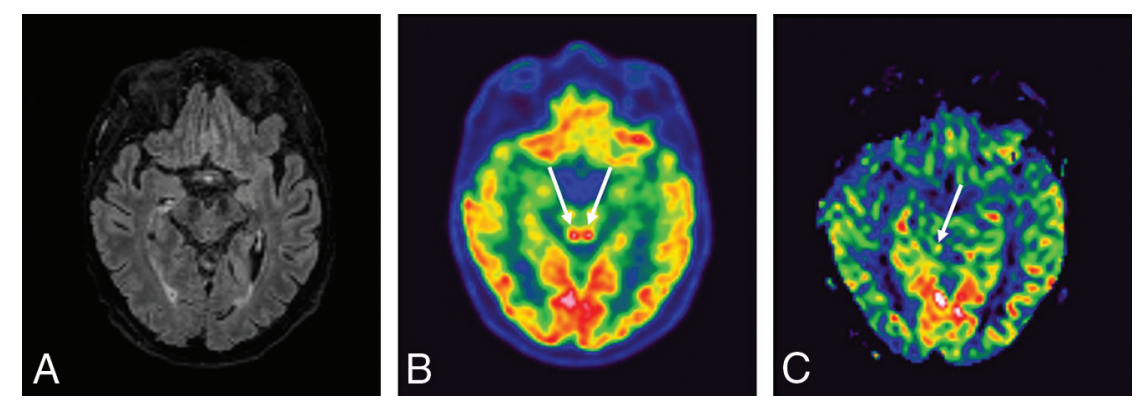

FIG 2. A 64-year-old man who had MR imaging for headaches, confusion, pyramidal tract signs, and pathologic awakening under sedation. These 3 images in the same patient showed a hyperactivation of colliculi in $\left[{ }^{18} \mathrm{~F}\right] \mathrm{FDG}-\mathrm{PET} / \mathrm{CT}(\mathrm{B})$, hyperperfusion in the brain perfusion sequence (CBF cartography), less intense and predominantly right-sided hyperperfusion on the follow-up MR imaging at 3 months $(C)$, and no abnormalities on the FLAIR sequence $(A)$.

Perfusion ASL sequences were performed on two 3T MR imaging scanners. On the $3 \mathrm{~T}$ Achieva dStream (Philips Healthcare), sequence parameters were as follows: 3D perfusion ASL, section thickness of $6 \mathrm{~mm}, 6-\mathrm{mm}$ spacing between slices, $80 \times 80$ matrix, $11 \mathrm{~ms} \mathrm{TE}, 90^{\circ}$ flip angle, $4235 \mathrm{~ms} \mathrm{TR}, 1$ echo, postlabeling delay $2000 \mathrm{~ms}$. On the 3T Signa HD (GE Healthcare), voxel size was $1.875 \times 1.875 \times 4 \mathrm{~mm}, 4599 \mathrm{~ms}$ TR,

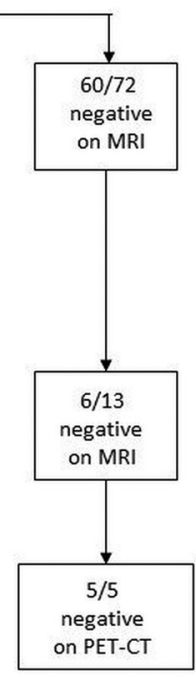

$9.8 \mathrm{~ms}$ TE, postlabeling delay $1525 \mathrm{~ms}$. The machine software was used to perform reconstructions (Software release HD23.0_V03_1614.b). Postprocessing was performed on MR imaging software and created final gray-scale DICOM images and CBF maps in color JPEG format.

At the time of analysis, the native sequence was first reviewed to ensure its good quality and the absence of artifacts, then systematically reconstructed by windowing with the same scale between the different patients (CBF between 0 and 200). ASL was systematically acquired before gadolinium injection. ${ }^{11}$ ASL was available in 72 patients in the acute phase of infection (Fig 1). Colliculi were analyzed qualitatively on CBF maps (for hyperperfusion, hyperintensity, nonhyperperfusion, and intensity indistinguishable from adjacent parenchyma) (Figs 2-4). The images were blindly interpreted independently by 2 neuroradiologists (A.C. and F.L., with 6 and 9 years of experience in neuroradiology, respectively), with total concordance. A brain $\left[{ }^{18} \mathrm{~F}\right]$ FDG-PET/ CT was performed for 13 patients on a Vision scanner (Siemens). The $\left[{ }^{18} \mathrm{~F}\right]$ FDG was injected intravenously at $2 \mathrm{MBq} / \mathrm{kg}$, after at least 6 hours of fasting (except ad libitum water intake) and capillary glycemia lower than $6.6 \mathrm{mmol} / \mathrm{L}$. Image acquisition was initiated 30 minutes after the $\left[{ }^{18} \mathrm{~F}\right]$ FDG injection, including low-dose noncontrast transmission CT scan followed by a PET/CT with an acquisition time of 10 minutes. PET data were reconstructed with and without CT-based attenuation correction (TrueX+TOF, 10 iterations, 5 subsets, zoom 2, matrix 880 , and Gaussian filter 2). Quantitative measurements were done on the PET/CT data. The metabolism of the right and left colliculi was measured by regions of interest and compared with that of the mesencephalon. A signal variation of more than $20 \%$ between the colliculi and the mesencephalon was considered hypermetabolic.

The PET/CT examinations were carried out on 2 patients during the acute phase of infection and on 12 patients during the 3-month follow-up period (1 patient had an initial PET/CT and follow-up) (Fig 1). The examinations were blindly interpreted independently 
by 2 nuclear medicine physicians (C.B. and I.J.N., with 7 and 15 years of experience, respectively) with total concordance.

ASL was acquired prospectively on 25 healthy controls with an age range of 21-61 (mean age, 42.32) on the same 3T Signa HD (GE Healthcare) with the same protocol at the same times, to see the usual collicular appearance.

\section{RESULTS}

Hyperperfusion of the colliculi, predominant in the lower colliculi, was observed in $12 / 72(16.7 \%)$ patients during the acute
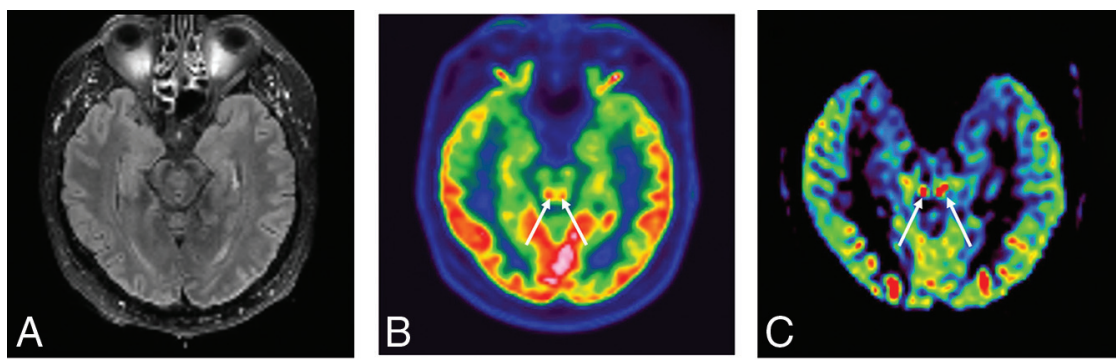

FIG 3. A 49-year-old man who had pathologic awakening under sedation and pyramidal tract signs. FLAIR sequence showed no hyperintensity of the colliculi $(A)$. They are hyperactivated in $\left[{ }^{18} \mathrm{~F}\right]$ FDG-PET/CT $(B)$ and hyperperfused in perfusion sequence (CBF cartography) (C).
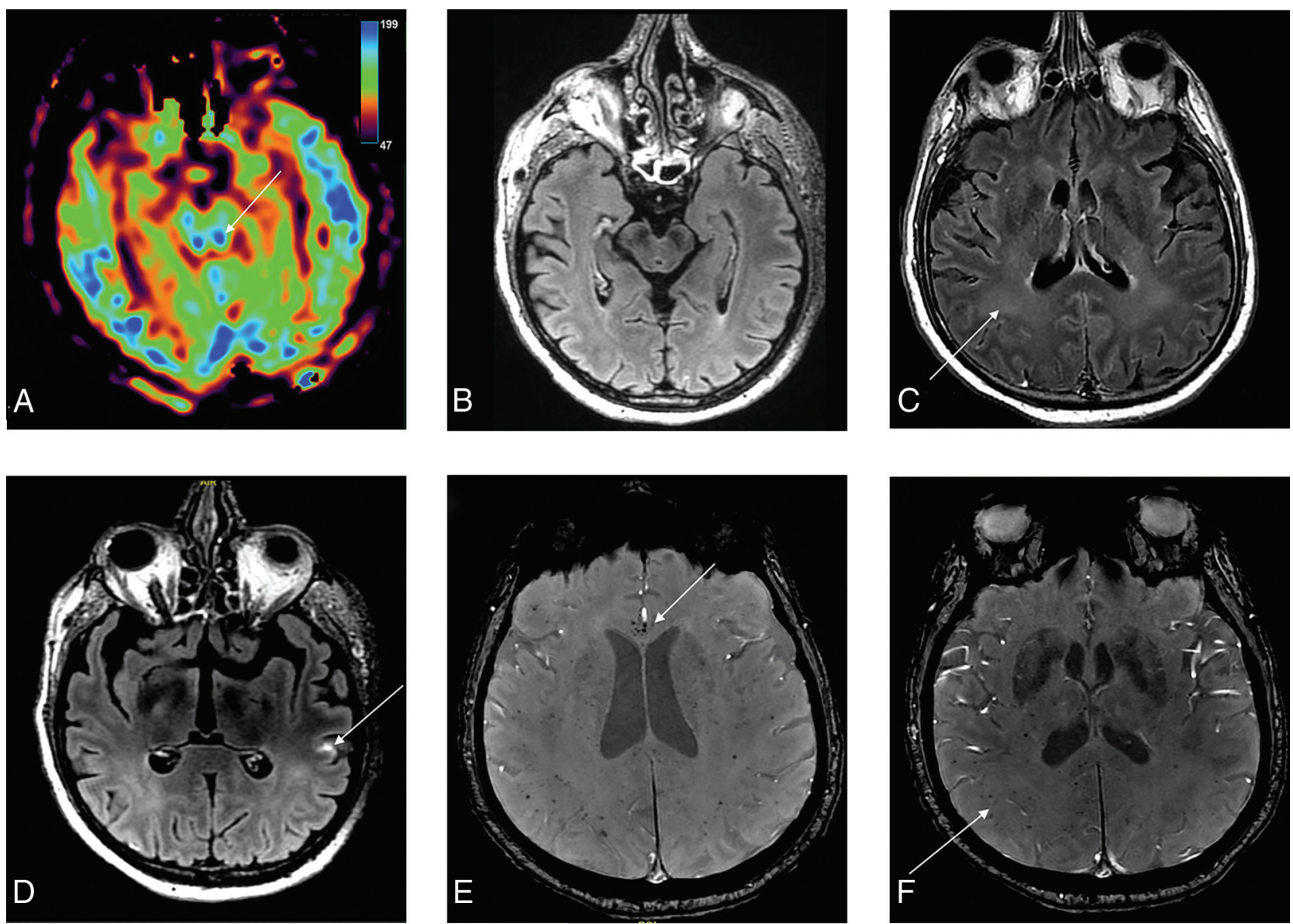

FIG 4. A 56-year-old man who presented with delayed awakening under sedation and had colliculi hyperperfusion on ASL perfusion sequence (A) without FLAIR hyperintensity (B). FLAIR postinjection of gadolinium showed diffuse hyperintensities of white matter $(C)$ and leptomeningeal enhancement $(D)$. Magnetic susceptibility sequence showed multiple microhemorrhages of the corpus callosum $(E)$ and of the periventricular white matter $(F)$. 
hyperperfusion for the variable "leptomeningeal enhancement" $(P=.016)$ (Online Supplemental Data). The colliculi showed no signal anomaly on all the other sequences performed.

Hyperactivation of the lower colliculi was confirmed in the 2 patients (100\%) who underwent PET/CT during the acute phase of infection (mean ratio colliculi/mesencephalon, 1.2955), and in 6/7 patients $(85.7 \%)$ who underwent PET/CT during the 3-month follow-up period (mean ratio colliculi/mesencephalon, 1.2947).

There was no significant difference between the groups with "hyperperfusion of the colliculi" and "no hyperperfusion" for the demographic variables. For clinical variables, seizures were more frequent in the group with hyperperfusion of the colliculi ( $P=$ $.004)$. Hyperperfusion of colliculi was not associated with a more severe clinical form of the infection nor with a more negative prognosis. However, there was a difference between the 2 groups in the biologic variables concerning the number of leukocytes at admission, which was higher in the group with hyperperfusion of the colliculi $(P=.02)$.

\section{DISCUSSION}

Lower colliculi play a role in hearing ${ }^{12}$ whereas the upper part contributes to visual coordination. ${ }^{13}$

Recent studies suggest that colliculi might be involved in coordinated autonomic and respiratory responses. ${ }^{14}$ The spectrum of pathologies affecting the colliculi is wide, rare, and poorly described. Tumors (glioma) have been described in this region. ${ }^{15,16}$ Colliculi can be affected in the context of vasculitis and necrotizing encephalitis. ${ }^{17}$ To the best of our knowledge, no examples have been reported in the literature, but inflammatory (neuromyelitis optica spectrum disorder), metabolic (mitochondriopathies), auto-immune (acute disseminated encephalomyelitis), or ischemic (vascular territory of perforating arteries of the basilar trunk) diseases are also possible.

In our study, $16.7 \%$ of patients had hyperperfusion of their colliculi during the acute phase of the infection, predominantly in the lower colliculi, without abnormality on the anatomic sequences. We tried to perform quantitative measures on each colliculus and on normal white and gray matter to have as a reference, but the structure of interest was too small to allow reliable measurements in MR imaging. The hyperactivation, well correlated with $\left[{ }^{18} \mathrm{~F}\right]$ FDG-PET/CT results, persisted despite discontinuation of sedation and ventilation, which excludes an iatrogenic etiology. ${ }^{18}$ This finding has not yet been described in the literature. This study raises the question of the underlying physiopathology of the involvement of the colliculi in COVID-19 infection. The reasons for this overactivation of the predominantly lower colliculi remain poorly understood. Angiotensin-converting enzyme 2, the main receptor for SARS-CoV-2, is expressed by endothelial cells, among others. ${ }^{19}$ The presence of angiotensin-converting enzyme 2 receptors within the colliculi has been described in the literature. ${ }^{20,21}$ It has been recently described that SARS-CoV-2 can infect endothelial cells with endotheliitis. $^{22}$

This hyperperfusion could reflect a viral gateway into the central nervous system or a direct viral involvement. Hyperleukocytosis could reinforce this hypothesis, but this was not supported by the analysis of the CSF. Lumbar punctures were performed on 7/12 patients, and the SARS-CoV-2 ribonucleic acid was never detected by reverse-transcriptase polymerase chain reaction. In addition, CSF analyses showed normal or slightly increased white blood cell count $\left(<10 / \mathrm{mm}^{3}\right)$. These results do not rule out the diagnosis because lumbar punctures were performed after the SARS-CoV-2 infection (mean, 26.2 days).

CNS immune surveillance and initial immune activation occurred in the subarachnoid space, which is a site for antigen presentation, lymphocyte accumulation and proliferation, and antibodies production. ${ }^{23}$ These resulted in an important local inflammatory infiltrate, which may explain the higher prevalence of leptomeningeal enhancement in the hyperperfusion of the colliculi group. Thus, leptomeningeal enhancements can be linked to inflammatory or immunologic responses, as previously described with some neurotropic viruses like human T-cell leukemia and HIV. ${ }^{24}$

One hypothesis would be that the cytokine storm caused by the infection involved these receptors and was responsible for their hyperactivation. This may be supported by the presence of significantly higher leukocyte levels at admission of patients with colliculi hyperperfusion (mean leukocyte rate, 11.069G/L versus $7.522 \mathrm{G} / \mathrm{L}, P=.002$ ). Another hypothesis would be that the colliculi are a preferential site for COVID-19 viral encephalitis (not supported by CSF analysis).

Among our 12 patients with colliculi hyperperfusion, 10 were hospitalized in the intensive care unit for severe COVID-19. These patients could have a cytokine release syndrome. It is a consequence of a rapid release of pro-inflammatory cytokines that increase the inflammatory response and could lead to neurotoxicity. The release of cytokines into the CNS increases the local inflammation, which leads to brain cell dysfunctions and edema. Moreover, cytokine release syndrome is associated with bloodbrain barrier and brain-CSF barrier breakdown and, therefore, with meningeal inflammation. That could also explain leptomeningeal enhancement.

\section{CONCLUSIONS}

MR imaging and PET revealed hyperactivation of the colliculi in patients with COVID-19 and the CSF analysis performed in a few patients did not detect SARS-CoV-2 ribonucleic acid. Moreover, no biologic or clinical correlation was found with the sign of hyperperfused inferior colliculi, the physiopathologic mechanisms of which remain unclear.

Disclosures: Jean-Christophe Brisset-UNRELATED: Employment: Median Technologies. Stéphane Kremer-UNRELATED: Board Membership: Bayer; Payment for Lectures Including Service on Speakers Bureaus: Roche, Biogen.

\section{REFERENCES}

1. Gulko E, Oleksk ML, Gomes W, et al. MRI brain findings in $\mathbf{1 2 6}$ patients with COVID-19: initial observations from a descriptive literature review. AJNR Am J Neuroradiol 2020;41:2199-203 CrossRef Medline

2. Yoon $\mathrm{BC}$, Buch $\mathrm{K}$, Lang $\mathrm{M}$, et al. Clinical and neuroimaging correlation in patients with COVID-19. AJNR Am J Neuroradiol 2020;41:1791-96 CrossRef Medline

3. Kremer S, Lersy F, Anheim M, et al. Neurologic and neuroimaging findings in COVID-19 patients: a retrospective multicenter study. Neurology 2020;95:e1868-82 CrossRef Medline 
4. Kremer S, Lersy F, de Seze J, et al. Brain MRI findings in severe COVID-19: a retrospective observational study. Radiology 2020;297: E242-51 CrossRef Medline

5. Delorme C, Paccoud O, Kas A, et al. COVID-19-related encephalopathy: a case series with brain FDG-PET/CT findings. Eur J Neurol 2020;27;2651-57 CrossRef Medline

6. Grimaldi S, Lagarde S, Harle JR, et al. Autoimmune encephalitis concomitant with SARS-CoV-2 infection: insight from (18)F-FDG PET imaging and neuronal autoantibodies. J Nucl Med 2020;61:1726-29 CrossRef Medline

7. Guedj E, Million M, Dudouet P, et al. F-FDG brain PET hypometabolism in post-SARS-CoV-2 infection: substrate for persistent/ delayed disorders? Eur J Nucl Med Mol Imaging 2020;48:592-95 CrossRef Medline

8. Noguchi T, Yakushiji Y, Nishihara M, et al. Arterial spin-labeling in central nervous system infection. Magn Reson Med Sci 2016;15:38694 CrossRef Medline

9. Sachs JR, Zapadka ME, Popli GS, et al. Arterial spin labeling perfusion imaging demonstrates cerebral hyperperfusion in antiNMDAR encephalitis. Radiol Case Rep 2017;12:833-37 CrossRef Medline

10. Haller S, Zaharchuk G, Thomas DL, et al. Arterial spin labeling perfusion of the brain: emerging clinical applications. Radiology 2016;281:337-56 CrossRef Medline

11. Deibler AR, Pollock JM, Kraft RA, et al. Arterial spin-labeling in routine clinical practice, part 1: technique and artifacts. AJNR Am J Neuroradiol 2008;29:1228-34 CrossRef Medline

12. Speck I, Arndt S, Thurow J, et al. F-FDG PET imaging of the inferior colliculus in asymmetric hearing loss. J Nucl Med 2020;61:41822 CrossRef Medline

13. Song JH, McPeek RM. Neural correlates of target selection for reaching movements in superior colliculus. J Neurophysiol 2015;113:141422 CrossRef Medline
14. Müller-Ribeiro FC, Goodchild AK, McMullan S, et al. Coordinated autonomic and respiratory responses evoked by alerting stimuli: Role of the midbrain colliculi. Respir Physiol Neurobiol 2016;226:8793 CrossRef Medline

15. Erratum to too much on your "plate"? Spectrum of pathologies involving the tectal plate. Can Assoc Radiol J 2020;71:NP1 CrossRef Medline

16. Gandhi N, Tsehmaister-Abitbol V, Glikstein R, et al. Too much on your "plate"? Spectrum of pathologies involving the tectal plate. Can Assoc Radiol J 2020;71:186-94 CrossRef Medline

17. Osborn AG. Osborn's Brain: Imaging, Pathology, and Anatomy. Elsevier; 2013

18. Tongjaroenbungam W, Jongkamonwiwat N, Cunningham J, et al Opioid modulation of GABA release in the rat inferior colliculus. BMC Neurosci 2004;5:31 CrossRef Medline

19. Catt KJ, Mendelsohn FA, Millan MA, et al. The role of angiotensin II receptors in vascular regulation. J Cardiovasc Pharmacol 1984;6 S575-86 CrossRef Medline

20. Barnes JM, Steward LJ, Barber PC, et al. Identification and characterisation of angiotensin II receptor subtypes in human brain. Eur J Pharmacol 1993;230:251-58 CrossRef Medline

21. Song K, Zhuo J, Allen AM, et al. Angiotensin II receptor subtypes in rat brain and peripheral tissues. Cardiology 1991;79 Suppl 1:4554 CrossRef Medline

22. Varga Z, Flammer AJ, Steiger P, et al. Endothelial cell infection and endotheliitis in COVID-19. Lancet 2020;395:1417-18 CrossRef Medline

23. Kivisäkk P, Imitola J, Rasmussen S, et al. Localizing central nervous system immune surveillance: meningeal antigen-presenting cells activate $\mathrm{T}$ cells during experimental autoimmune encephalomyelitis. Ann Neurol 2009;65:457-69 CrossRef Medline

24. Absinta M, Cortese IC, Vuolo L, et al. Leptomeningeal gadolinium enhancement across the spectrum of chronic neuroinflammatory diseases. Neurology 2017;88:1439-44 CrossRef Medline 